\title{
La intervención de la Administración en la seguridad ciudadana: los espectáculos públicos. Especial referencia a la Comunidad de Madrid
}

\author{
Augusto González Alonso \\ Cuerpo Superior de Administradores Civiles del Estado
}

\begin{abstract}
Sumario: 1. COMPETENCIAS DEL ESTADO Y LAS COMUNIDADES AUTÓNOMAS EN MATERIA DE ESPECTÁCULOS PÚBLICOS Y ACTIVIDADES RECREATIVAS. - 2. INTERVENCIÓN DEL ESTADO EN LOS ESPECTÁCULOS PÚBLICOS Y ACTIVIDADES RECREATIVAS. - 3. COMPETENCIA DE LA COMUNIDAD DE MADRID EN MATERIA DE ESPECTÁCULOS PÚBLICOS Y ACTIVIDADES RECREATIVAS. - 4. NORMATIVA DE LA COMUNIDAD DE MADRID EN MATERIA DE CONTROL DE ACCESO A ESPECTÁCULOS PÚBLICOS Y ACTIVIDADES RECREATIVAS.
\end{abstract}

\section{COMPETENCIAS DEL ESTADO Y LAS COMUNIDADES AUTÓNOMAS EN MATERIA DE ESPECTÁCULOS PÚBLICOS Y ACTIVIDADES RECREATIVAS}

Es preciso iniciar este comentario distinguiendo las competencias estatales y autonómicas en materia de espectáculos públicos y actividades recreativas, o en general sobre el ocio. Si resulta complejo incardinar esta materia en alguno de los títulos competenciales que el artículo 148.1 de la Constitución Española (en adelante, $\mathrm{CE}$ ) atribuye a las comunidades autónomas, más complejo aún es definir el marco constitucional y competencial del Estado, en atención a la redacción de las distintas reglas del artículo 149.1 CE.

Se comenzará por el análisis de las competencias autonómicas con el propósito didáctico de facilitar la inclusión de la materia «ocio» en alguno de los títulos competenciales atribuidos al Estado. Así, si bien el artículo 148.1,19. ${ }^{a} \mathrm{CE}$ atribuye de forma expresa la competencia a las comunidades autónomas en materia de promoción del deporte y de la adecuada utilización del ocio, no son pocos los Estatutos de Autonomía que asumen miméticamente esa redacción y lo reproducen en sus normas estatutarias, añadiendo términos en íntima conexión con aquél como los espectáculos públicos o las actividades recreativas. Resulta evidente que el término «ocio» es demasiado amplio y puede abarcar un gran número de actividades que ocupan el tiempo libre de una persona, como es definido por la Real Academia de la Lengua. Es más, el ocio es identificado por esta institución con la «diversión u ocupación reposada, especialmente en obras de ingenio, porque éstas se toman regularmente por descanso de otras tareas». Esta definición conduce el término a otros ámbitos y materias (también competenciales, por cierto) como la cultura, que es un instrumento 
útil y loable de la vida ociosa, así como el deporte no entendido en su dimensión profesional.

La cultura, como conjunto de modos de vida y costumbres, conocimientos y grado de desarrollo artístico, científico o industrial de una época y de un grupo social, se configura como un concepto amplio, poliédrico y omnicomprensivo de toda actividad humana que conforma un acervo de conocimientos, técnicas, costumbres y modos de vida que incluye otras muchas materias que, ya desde el punto de vista competencial, la Constitución Española atribuye a las comunidades autónomas: es el caso de las ferias interiores (artículo 148.1,12. ${ }^{\mathrm{a}} \mathrm{CE}$ ), la artesanía (artículo 148.1,14. ${ }^{a} \mathrm{CE}$ ), los museos, bibliotecas y conservatorios de música de interés para la comunidades autónomas (artículo 148.1,15. ${ }^{\mathrm{a}} \mathrm{CE}$ ), el patrimonio monumental de interés de la comunidad autónoma (artículo 148.1,16. ${ }^{\mathrm{a}} \mathrm{CE}$ ) y hasta la lengua, que el artículo $148.1,17 .{ }^{\mathrm{a}} \mathrm{CE}$ atribuye a las comunidades autónomas en lo que respecta a su enseñanza cuando cuenten con lengua propia.

Por lo que respecta al deporte, el artículo $148.1,19 .{ }^{\mathrm{a}} \mathrm{CE}$, que también es un instrumento de inversión del tiempo de ocio, atribuye a las comunidades autónomas la competencia de su promoción.

Sin detenernos en este análisis competencial más de lo imprescindible, por no ser objeto concreto de este artículo, puede decirse que no hay pronunciamientos de la doctrina constitucional sobre el significado y alcance del artículo 148.1,19. ${ }^{a}$ en relación con la «adecuada utilización del ocio», aunque no han faltado los conflictos positivos de competencias en los que las comunidades autónomas han invocado esta regla competencial frente al Estado, aunque siempre acompañado de la alegación de otros títulos constitucionales y estatutarios. Algunas voces de la doctrina más autorizada ${ }^{1}$ entienden que la «adecuada utilización del ocio remite a la lícita autodeterminación de la propia conducta y, por consiguiente, al libre desarrollo de la personalidad (artículo 10.1 CE) y a la libertad personal (artículo 17.1 CE), que son por principio ámbitos refractarios a la intervención de los poderes públicos».

Un peinado de los distintos Estatutos de Autonomía en relación con la materia de ocio o espectáculos públicos, arroja el siguiente resultado analítico:

- Ley Orgánica 5/1982, de 1 de julio, del Estatuto de Autonomía de la Comunidad Valenciana: artículo 49.1. La Generalitat tiene competencia exclusiva sobre las siguientes materias:

28. ${ }^{\mathrm{a}}$ Deportes y ocio.

30. ${ }^{a}$ Espectáculos.

1 Miguel CASINO RUBIO, en la obra colectiva Comentarios a la Constitución Española, XXX Aniversario, Fundación Wolters Kluwer España, diciembre 2008. 
- Ley Orgánica 1/1981, de 6 de abril, Estatuto de Autonomía de Galicia: artículo 27: otorga a la comunidad autónoma gallega la competencia exclusiva de las siguientes materias:

22. La promoción del deporte y la adecuada utilización del ocio.

Las competencias mencionadas fueron ampliadas por la Ley Orgánica 16/1995, de 27 de diciembre, de transferencia de competencias a la Comunidad Autónoma Gallega, de modo que se transfirieron competencias exclusivas en materia de espectáculos públicos, si bien el artículo 5 dispuso que «De conformidad con lo dispuesto en el número 29 del apartado uno del artículo 149 de la Constitución, el contenido de la competencia sobre espectáculos públicos se entiende sin perjuicio de la competencia estatal sobre seguridad pública. 2. Queda reservada al Estado la facultad de dictar normas que regulen los espectáculos taurinos.»

- Ley Orgánica 3/1979, de 18 de diciembre, del Estatuto de Autonomía del País Vasco: artículo 10: la Comunidad Autónoma del País Vasco tiene competencia exclusiva en las siguientes materias:

36. Turismo y deporte. Ocio y esparcimiento.

38. Espectáculos.

- Ley Orgánica 13/1982, de 10 de agosto, de reintegración y amejoramiento del régimen foral de Navarra: artículo 44: Navarra tiene competencia exclusiva sobre las siguientes materias:

14. Promoción del deporte y de la adecuada utilización del ocio.

15. Espectáculos.

- Ley Orgánica 4/1982, de 9 de junio, de Estatuto de Autonomía de Murcia: artículo 10.1. Corresponde a la Comunidad Autónoma de Murcia la competencia exclusiva en las siguientes materias:

17. Promoción del deporte y de la adecuada utilización del ocio.

24. Espectáculos públicos.

- Ley Orgánica 3/1983, de 25 de febrero, de Estatuto de Autonomía de Madrid: artículo 26.1. La Comunidad de Madrid, en los términos establecidos en el presente Estatuto, tiene competencia exclusiva en las siguientes materias:

1.22. Deporte y ocio.

1.30. Espectáculos públicos. 
- Ley Orgánica 3/1982, de 9 de junio, de Estatuto de Autonomía de La Rioja: artículo 8.1. Corresponde a la Comunidad Autónoma de La Rioja la competencia exclusiva en las siguientes materias:

27. La promoción del deporte y de la adecuada utilización del ocio.

29. Espectáculos.

- Ley Orgánica 1/1995, de 13 de marzo, de Estatuto de Autonomía de Ceuta: artículo 21.1. La ciudad de Ceuta ejercerá competencias sobre las materias que a continuación se relacionan, con el alcance previsto en el apartado 2 de este artículo:

17. Promoción del deporte y de la adecuada utilización del ocio.

2. En relación con las materias enumeradas en el apartado anterior, la competencia de la ciudad de Ceuta comprenderá las facultades de administración, inspección y sanción, y, en los términos que establezca la legislación general del Estado, el ejercicio de la potestad normativa reglamentaria.

Artículo 22.1. Corresponde a la ciudad de Ceuta la ejecución de la legislación del Estado en las siguientes materias:

5. ${ }^{a} \quad$ Publicidad y espectáculos.

- Ley Orgánica 2/2007, de 19 de marzo, de reforma del Estatuto de Autonomía para Andalucía: artículo 26.1. En el ejercicio del derecho constitucional al trabajo, se garantiza a todas las personas:

d) El derecho al descanso y al ocio.

Artículo 72. Deportes, espectáculos y actividades recreativas.

2. Corresponde a la Comunidad Autónoma la competencia exclusiva en materia de espectáculos y actividades recreativas que incluye, en todo caso, la ordenación del sector, el régimen de intervención administrativa y el control de todo tipo de espectáculos en espacios y locales públicos.

- Ley Orgánica 7/1981, de 30 de diciembre, de Estatuto de Autonomía del Principado de Asturias: artículo 10.1. El Principado de Asturias tiene la competencia exclusiva en las materias que a continuación se señalan:

23. Deporte y ocio.

28. Espectáculos públicos.

- Ley Orgánica 14/2007, de 30 de noviembre, de reforma del Estatuto de Autonomía de Castilla y León: artículo 70.1. La Comunidad de Castilla y León tiene competencia exclusiva en las siguientes materias: 
32. Espectáculos públicos y actividades recreativas.

33. Promoción de la educación física, del deporte y del ocio.

- Ley Orgánica 10/1982, de 10 de agosto, de Estatuto de Autonomía de Canarias: artículo 30: la Comunidad Autónoma de Canarias, de acuerdo con las normas del presente Estatuto, tiene competencia exclusiva en las siguientes materias:

20. Deporte, ocio y esparcimiento. Espectáculos.

- Ley Orgánica 2/1995, de 13 de marzo, de Estatuto de Autonomía de Melilla: artículo 21.1. La ciudad de Melilla ejercerá competencias sobre las materias que a continuación se relacionan, con el alcance previsto en el apartado 2 de este artículo:

17. Promoción del deporte y de la adecuada utilización del ocio.

2. En relación con las materias enumeradas en el apartado anterior, la competencia de la ciudad de Melilla comprenderá las facultades de administración, inspección y sanción, y, en los términos que establezca la legislación general del Estado, el ejercicio de la potestad normativa reglamentaria.

Artículo 22.1. Corresponde a la ciudad de Melilla la ejecución de la legislación del Estado en las siguientes materias:

5. ${ }^{a} \quad$ Publicidad y espectáculos.

- Ley Orgánica 1/1983, de 25 de febrero, de Estatuto de Autonomía de Extremadura: artículo 7.1. Corresponde a la Comunidad Autónoma la competencia exclusiva en las siguientes materias:

18. Promoción del deporte y la adecuada utilización del ocio.

24. Espectáculos públicos.

- Ley Orgánica 9/1982, de 10 de agosto, de Estatuto de Autonomía de Castilla-La Mancha: artículo 31.1. La Junta de Comunidades de Castilla-La Mancha asume las siguientes competencias exclusivas:

19. Promoción del deporte y de la adecuada utilización del ocio.

23. Espectáculos públicos.

- Ley Orgánica 1/2007, de 28 de febrero, de reforma del Estatuto de Autonomía de las Illes Balears: artículo 12.3. Las instituciones propias de la Comunidad Autónoma de las Illes Balears, para cumplir las finalidades que les son propias y en el marco de las competencias que les atribuye este Estatuto, deben promover, como principios rectores de la política económica y social, el desa- 
rrollo sostenible encaminado a la plena ocupación, la cohesión social y el progreso científico y técnico de manera que asegure a toda la ciudadanía el acceso a los servicios públicos y el derecho a la salud, la educación, la vivienda, la protección social, el ocio y la cultura.

Artículo 30: La Comunidad Autónoma tiene la competencia exclusiva en las siguientes materias, sin perjuicio de lo dispuesto en el artículo 149.1 de la Constitución:

12. Deporte y ocio. Fomento, planificación y coordinación de las actividades deportivas y de ocio. Regulación y declaración de utilidad pública de las entidades deportivas.

22. Pesca y actividades recreativas en aguas interiores, cría y recogida de marisco, acuicultura.

31. Espectáculos y actividades recreativas.

Artículo 70. Son competencias propias de los Consejos Insulares, además de las que les vengan atribuidas por la legislación estatal, las siguientes materias:

11. Espectáculos públicos y actividades recreativas.

- Ley orgánica 8/1981, de 30 de diciembre, de Estatuto de Autonomía de Cantabria: artículo 24: la Comunidad Autónoma de Cantabria tiene competencia exclusiva en las materias que a continuación se señalan, que serán ejercidas en los términos dispuestos en la Constitución:

Promoción del deporte y de la adecuada utilización del ocio.

Espectáculos públicos.

- Ley Orgánica 5/2007, de 20 de abril, de reforma del Estatuto de Autonomía de Aragón: artículo 71. En el ámbito de las competencias exclusivas, la Comunidad Autónoma de Aragón ejercerá la potestad legislativa, la potestad reglamentaria, la función ejecutiva y el establecimiento de políticas propias, respetando lo dispuesto en los artículos 140 y 149.1 de la Constitución. Corresponde a la Comunidad Autónoma la competencia exclusiva en las siguientes materias:

54. ${ }^{\text {a }}$ Espectáculos y actividades recreativas, que incluye, en todo caso, la ordenación general del sector, el régimen de intervención administrativa y la seguridad y el control de todo tipo de espectáculos en espacios y establecimientos públicos.

- Ley Orgánica 6/2006, de 19 de julio, de reforma del Estatuto de Autonomía de Cataluña: artículo 84.2. Los gobiernos locales de Cataluña tienen en todo caso competencias propias sobre las siguientes materias en los términos que determinen las leyes: 
k) La regulación y la gestión de los equipamientos deportivos y de ocio y promoción de actividades.

Artículo 141.3: Corresponde a la Generalitat la competencia exclusiva en materia de espectáculos y actividades recreativas, que incluye, en todo caso, la ordenación del sector, el régimen de intervención administrativa y el control de todo tipo de espectáculos en espacios y locales públicos.

Artículo 134.1. Corresponde a la Generalitat la competencia exclusiva en materia de deporte, que incluye en todo caso:

j) La regulación en materia de prevención y control de la violencia en los espectáculos públicos deportivos, respetando las facultades reservadas al Estado en materia de seguridad pública.

Pues bien, sobre el título cultura ya es conocido por los estudiosos de la materia que se trata de una competencia concurrente, tal y como ha sido consagrado por el Tribunal Constitucional en varios pronunciamientos ${ }^{2}$, en los que reconoce que la competencia sobre cultura no puede ser omnímoda y excluyente y que «la cultura es algo de la competencia propia e institucional tanto del Estado como de las comunidades autónomas», razón por la que el artículo 149.2 $\mathrm{CE}$, «después de reconocer la competencia autonómica, se afirma una competencia estatal, poniendo el acento en el servicio de la cultura como deber y atribución esencial». El Alto Tribunal ha entendido que se produce «una competencia estatal y una competencia autonómica en el sentido de que más que un reparto competencial vertical, lo que se produce es una concurrencia de competencias ordenada a la preservación y estímulo de los valores culturales propios del cuerpo social desde la instancia pública correspondiente. Que en materia cultural es destacada la acción autonómica es algo inherente a la Comunidad (artículo $2 \mathrm{CE}$ ). Que a su vez al Estado compete también una competencia que tendrá, ante todo, un área de preferente atención en la preservación del patrimonio cultural común, pero también en aquello que precise de tratamientos generales o que hagan menester esa acción pública cuando los bienes culturales pudieran no lograrse desde otras instancias, es algo que está en la línea de la proclamación que se hace en el indicado precepto constitucional».

Por lo que respecta al Estado, el artículo 149.2 CE establece que, sin perjuicio de las competencias que puedan asumir las comunidades autónomas, el Estado considerará el servicio de la cultura como deber y atribución esencial y facilitará la comunicación cultural de las comunidades autónomas, de acuerdo con ellas. La cultura, por tanto, tiene múltiples manifestaciones, que a veces se identifican con un ámbito concreto en la Constitución, como cuando se refiere al patrimonio cultural, histórico, artístico y monumental o cuando se refiere a

2 Sentencias del Tribunal Constitucional número 49/1984, de 25 de abril; número 157/1985, de 15 de noviembre; y número 106/1987, de 25 de junio. 
los museos, bibliotecas y archivos de titularidad estatal (ex artículo 149.1,28. ${ }^{\text {a }}$ $\mathrm{CE}$ ), y otras veces no se identifican con ámbito concreto alguno pero se deduce sustantivamente su relación con ella, como cuando se tratan cuestiones relacionadas con el ocio y los espectáculos públicos. En definitiva, la cultura, como un instrumento en que puede invertirse el tiempo de ocio por el ser humano, es un título competencial horizontal y concurrente entre el Estado y las comunidades autónomas.

\section{INTERVENCIÓN DEL ESTADO EN LOS ESPECTÁCULOS PÚBLICOS Y ACTIVIDADES RECREATIVAS}

El ejercicio de lo que se conoce como policía de espectáculos es una de las principales manifestaciones de la intervención de la Administración pública en la sociedad, con normas que regulan de forma prolija aspectos como la seguridad de los edificios e instalaciones, medidas contra incendios, horarios de los espectáculos y actividades, régimen de licencias y autorizaciones de todo tipo, régimen de inspecciones y de ejercicio de la potestad sancionadora, entre otros.

La normativa estatal que regula esta materia lo constituye, en el ejercicio de la competencia exclusiva del Estado en materia de seguridad pública (ex artículo 149.1,29. ${ }^{\text {a }}$ CE), la Ley Orgánica 1/1992, de 21 de febrero, sobre Protección de la Seguridad Ciudadana, norma que reconoce la competencia del Gobierno, a través de las autoridades y de las Fuerzas y Cuerpos de Seguridad a sus órdenes, para proteger el libre ejercicio de los derechos y libertades y garantizar la seguridad ciudadana, crear y mantener las condiciones adecuadas a tal efecto, y remover los obstáculos que lo impidan. Para ello, la norma regula unas medidas de acción preventiva y vigilancia, las actuaciones que las autoridades competentes pueden adoptar para el mantenimiento y el restablecimiento de la seguridad ciudadana, y el régimen sancionador aplicable para los supuestos de incumplimiento. Pues bien, dentro de las medidas de acción preventiva y vigilancia establecidas, la norma dedica un solo precepto, el artículo 8, a los espectáculos públicos y las actividades recreativas. Así, el mismo dispone que:

«1. Todos los espectáculos y actividades recreativas de carácter público quedarán sujetos a las medidas de policía administrativa que dicte el Gobierno, en atención a los fines siguientes:

a) Garantizar la seguridad ciudadana frente a los riesgos que, para las personas o sus bienes, se puedan derivar del comportamiento de quienes organicen un espectáculo o actividad recreativa, participen en ellos o los presencien.

b) Asegurar la pacífica convivencia cuando pudiera ser perturbada por la celebración del espectáculo o el desarrollo de la actividad. 
c) Limitar las actividades de los locales y establecimientos públicos a las que tuvieren autorizadas, e impedir, en todo caso, el ejercicio en ellos de cualesquiera otras que estuvieren prohibidas.

d) Fijar las condiciones a las que habrán de ajustarse la organización, venta de localidades y horarios de comienzo y terminación de los espectáculos o actividades recreativas, siempre que sea necesario, para que su desarrollo transcurra con normalidad.

2. Los espectáculos deportivos quedarán, en todo caso, sujetos a las medidas de prevención de la violencia que se disponen en el Título IX de la Ley 10/1990, de 15 de octubre, del Deporte».

En desarrollo de dicho precepto, el Gobierno aprobó el Real Decreto 2816/1982, de 27 de agosto, por el que se regula el Reglamento General de Policía de Espectáculos y Actividades Recreativas, norma que ha experimentado dos importantes modificaciones en los años 2006 y 2007 debido a: por un lado, la aprobación del Real Decreto 314/2006, de 17 de marzo, por el que se aprueba el Código Técnico de la Edificación, haciendo innecesaria la regulación en aquella norma de los requisitos y condiciones exigibles para la construcción o transformación de edificios y locales para destinarlos a espectáculos propiamente dichos, ya que se regulaban aspectos como la fachada y salida a vías públicas de los mismos, puertas de emergencia, vestíbulos de entrada y en los distintos pisos, escaleras, ascensores, pasillos y materiales de las armaduras, cubiertas y entreplantas, así como las precauciones y medidas contra incendios; por otro lado, debido a la aprobación del Real Decreto 393/2007, de 23 de marzo, por el que se aprueba la Norma Básica de Autoprotección de los centros, establecimientos y dependencias dedicados a actividades que puedan dar origen a situaciones de emergencia, con lo que se hizo innecesaria la regulación en el Real Decreto 2816/1982 de dicha norma básica y de un plan de emergencia, previo informe de la Junta Central Consultiva de Espectáculos y Actividades Recreativas. En líneas generales, el Real Decreto 2816/1982 regula los aspectos netamente jurídicos y generales de los espectáculos públicos, las actividades recreativas y los establecimientos públicos en general, sin perjuicio de los reglamentos técnicos especiales que se aprueben para cada espectáculo o grupos de espectáculos concretos. Se trata de una norma aplicable a los espectáculos, deportes, juegos, recreos y establecimientos destinados al público (previstos en un anexo de contenido muy amplio al respecto) y a las demás actividades de características análogas, con independencia de que sean de titularidad pública o privada y de que se propongan o no finalidades lucrativas. En todo caso, el reglamento deja a salvo las disposiciones que puedan establecer, en el ejercicio de sus competencias, otros órganos del Estado, de las comunidades autónomas y de las entidades locales.

Teniendo en cuenta que muchos de estos aspectos afectan a otras materias en las que las comunidades autónomas ostentan competencias, cada una de ellas ha venido aprobando sus propias normas de regulación de los espectáculos 
públicos y las actividades recreativas, con un contenido sustantivo semejante al recogido en el reglamento estatal, adaptado a sus peculiares circunstancias sociales, económicas y culturales.

\section{COMPETENCIA DE LA COMUNIDAD DE MADRID EN MATERIA DE ESPECTÁCULOS PÚBLICOS Y ACTIVIDADES RECREATIVAS}

Para comentar la competencia autonómica sobre esta materia es preciso acudir, en primer lugar, al Estatuto de Autonomía de la Comunidad de Madrid, cuyo artículo 26.1.30 le atribuye competencia exclusiva en materia de espectáculos públicos.

En desarrollo de dichas previsiones, la Asamblea de Madrid aprobó la Ley 17/1997, de 4 de julio, de Espectáculos Públicos y Actividades Recreativas. La finalidad de la misma era superar algunas lagunas y deficiencias del Real Decreto estatal de 1982 ya mencionado, sobre todo en lo que respecta al régimen sancionador y la anulación de varias sanciones por parte del Tribunal Supremo dado el insuficiente rango normativo de la norma para regular tales previsiones. La ley autonómica persigue un alcance adicional al del reglamento estatal por cuanto el sector del ocio ha ido cobrando cada vez mayor importancia económica y social en la sociedad y por la necesidad de abarcar ámbitos hasta entonces excluidos de la normativa vigente, como fueron la protección de la juventud y la infancia, la del medio ambiente, la de minusválidos, la protección de los espectadores y el respeto hacia las minorías. La norma tiene un alcance global por cuanto se aplica a todos los espectáculos públicos, actividades recreativas y establecimientos en los que se celebren, si bien, dada la imposibilidad material de regular todas las cuestiones que plantean los espectáculos públicos, hay una remisión a la normativa especial reguladora de ciertos espectáculos, establecimientos y actividades.

En líneas generales, la Ley 17/1997 es de aplicación a los espectáculos públicos y actividades recreativas que se desarrollen en el territorio de la Comunidad de Madrid, tengan o no finalidad lucrativa, se realicen de forma habitual o esporádica y con independencia de que sus titulares u organizadores sean entidades públicas, o personas físicas o jurídicas privadas. La norma define también lo que hay que entender por espectáculo público y por actividad recreativa, que coinciden en sus destinatarios (el público en general) y que forman parte del ocio en su dimensión artística, cultural o deportiva.

Asimismo, la norma autonómica prohíbe ciertos espectáculos y actividades y recoge una serie de normas que contemplan los requisitos y condiciones técnicas que han de reunir los locales, recogiendo en una sola norma todas las autorizaciones o licencias que, en ejercicio de la potestad de policía, han de 
exigir las Administraciones Públicas autonómica o local a esos espacios públicos. Entre ellos destacan las disposiciones que exigen que los locales reúnan todos los requisitos imprescindibles para garantizar la seguridad del público asistente, la higiene de las instalaciones y la evitación de molestias a terceros.

Precisamente es la garantía de la seguridad de los usuarios o clientes lo que dio lugar a la aprobación por el Ejecutivo autonómico del Decreto 163/2008, de 29 de diciembre, por el que se regula la actividad de control de acceso a espectáculos públicos y actividades recreativas, que se comenta específicamente en otro apartado de este artículo. La norma exige que esos locales y establecimientos tengan suscrito un contrato de seguro que cubra los riesgos de incendio y de responsabilidad civil por daños, así como un plan de emergencia, que cuenten con las licencias oportunas (las municipales que correspondan, primero, y la de funcionamiento, después) y que exhiban un documento en el que consten los datos de la licencia concedida. Además, la disposición regula las autorizaciones estatales, autonómicas y municipales preceptivas con las que han de contar ciertos espectáculos y actividades, y se establecen ciertas normas que regulan la actividad, tales como el horario general y de apertura, la necesaria existencia de libros de reclamaciones, el ejercicio del derecho de admisión y los derechos que protegen al consumidor y al usuario, entre otros. La norma se completa con una prolija regulación de la potestad inspectora y del régimen sancionador aplicable en caso de incurrir en la comisión de infracciones en esta materia.

Se recoge en un anexo el catálogo de espectáculos públicos, actividades recreativas, establecimientos, locales e instalaciones a los que son de aplicación la ley, catálogo que fue sustituido por el aprobado por un Decreto del Consejo de Gobierno ${ }^{3}$ de 22 de octubre de 1998, de modo que su alcance es muy amplio, llegando el artículo 1.2 de la ley a incluir «cualesquiera otros de naturaleza análoga». En consecuencia, parece que la norma no sólo se aplica a los locales donde tengan lugar espectáculos públicos o actividades recreativas, sino también a todos los establecimientos enumerados en el anexo.

El nuevo catálogo aprobado en 1998 pretendía adecuar la clasificación normativa a la realidad de los diferentes tipos de establecimientos existentes, completar la clasificación con una definición de cada uno de los diferentes tipos de espectáculos, locales e instalaciones para clarificar el panorama y facilitar la actuación de los Ayuntamientos a la hora de conceder las licencias de funcionamiento. Asimismo, el regulador autonómico aprovecha para desarrollar parcialmente la Ley 17/1997, que todavía no cuenta con reglamento de desarrollo y ejecución. En consecuencia, el catálogo que recoge el Decreto 184/1998 incluye locales, recintos, instalaciones y establecimientos en los que no sólo se desarrollan espectáculos y actividades recreativas, sino otras actividades, siempre

3 Decreto 184/1998, de 22 de octubre, por el que se aprueba el Catálogo de Espectáculos Públicos, Actividades Recreativas, Establecimientos, Locales e Instalaciones. 
que en todo caso su titular esté en posesión de la correspondiente licencia de funcionamiento. Obsérvese, por ejemplo, cómo la disposición adicional primera del meritado Decreto exige la instalación de ciertos aparatos de insonorización en los bares especiales (entre los que se incluyen los que no celebran actuaciones musicales en directo). Asimismo, todo el apartado $\mathrm{V}$ del anexo I hace referencia, en general, a otros establecimientos abiertos al público, tales como tabernas y bodegas, cafeterías, bares, chocolaterías, heladerías o terrazas, entre otros. El apartado III del anexo II ya aclara que se procede a clasificar y definir los recintos, instalaciones, locales y establecimientos abiertos al público que, de forma profesional y habitual, se dedican a proporcionar, a cambio de precio, comidas o bebidas a los concurrentes para ser consumidas en aquéllos, los cuales son definidos a los efectos del Decreto 184/1998, sin perjuicio de lo establecido en otras normas sectoriales que disciplinen aspectos de los mismos distintos de los regulados en aquél.

\section{NORMATIVA DE LA COMUNIDAD DE MADRID EN MATERIA DE CONTROL DE ACCESO A ESPECTÁCULOS PÚBLICOS Y ACTIVIDADES RECREATIVAS}

Como ya se anticipó en un apartado anterior, el sustantivo que permite conectar el Decreto 163/2008, de 29 de diciembre, del Consejo de Gobierno de la Comunidad de Madrid, por el que se regula la actividad de control de acceso a espectáculos públicos y actividades recreativas, con la norma legal de la que trae causa (la Ley 17/1997, de 4 de julio) es la «seguridad». El artículo 6 de la ley autonómica citada exige a los locales y establecimientos que reúnan los requisitos y condiciones que garanticen la seguridad del público asistente, lo que se despliega en el apartado 2 de dicho precepto en una garantía de seguridad para el citado público asistente, los trabajadores, los ejecutantes y los bienes.

En todo caso, hay que destacar que el Decreto 163/2008 que se comentará en este apartado tiene por objeto la regulación de la actividad de control de acceso en espectáculos y actividades recreativas que dispongan de dicho servicio, con la finalidad de garantizar la seguridad de los usuarios en el interior de los locales o recintos, de sus dependencias anexas y la entrada a los mismos. No todos los locales y establecimientos están obligados a contar con personal que controle el acceso, por lo que el amplio ámbito de aplicación establecido en el artículo 1 de la Ley 17/1997 se restringe a los establecimientos, locales e instalaciones en los que se celebren conciertos, los cafés-espectáculos, las salas de fiesta, las discotecas y salas de baile, los bares especiales con o sin actuaciones en directo (en los que sólo hay ambientación musical) y los espectáculos y/o actividades recreativas de carácter extraordinario.

Las funciones que comprende el control de acceso, que será ejercido por personal de control contratado y bajo la dependencia de la persona titular u or- 
ganizadora de esas actividades, son: dirigir y asegurar la entrada pacífica de personas al establecimiento, comprobar la edad de las personas (recuérdese que la admisión de un menor está tipificada como falta grave en el artículo 38.6 Ley 17/1997), controlar la adquisición de la entrada o localidad por los asistentes, controlar que no se exceda el aforo autorizado (también sancionado como falta muy grave o grave en los artículos 37 y 38 de la Ley 17/1997 en función de que comporte un grave riesgo para la seguridad de personas o bienes o no lo comporte), requerir la intervención del servicio de vigilancia del establecimiento, si lo tuviera, o en su defecto, de las fuerzas y cuerpos de seguridad del Estado, controlar el tránsito de zonas reservadas, vigilar que las bebidas se consuman en el interior del local, prohibir el acceso del público a partir del horario de cierre (tipificado como falta leve, ex artículo 39.1 Ley 17/1997), informar al personal de vigilancia o a las fuerzas y cuerpos de seguridad del Estado de las alteraciones del orden, y permitir y colaborar en las inspecciones o controles reglamentarios (la obstaculización de estas inspecciones está tipificada como falta muy grave, ex artículo 37.12 Ley 17/1997).

Para proceder a la contratación de este personal, el Decreto exige que se cumplan unos requisitos mínimos, como son tener la mayoría de edad, la nacionalidad española, de alguno de los países de la Unión Europea o estar en posesión del permiso de residencia y trabajo, carecer de antecedentes penales y haber superado unas pruebas en la Academia de Policía Local de la Comunidad de Madrid, consistentes en un test psicológico y un test de conocimiento en materia de derechos fundamentales, derecho de admisión, medidas de seguridad en los establecimientos, horarios de cierre y régimen jurídico de los menores de edad. Una vez superadas estas pruebas, se expedirá un certificado acreditativo que tendrá una validez de cinco años, a partir de los cuales es preciso su renovación mediante la superación, de nuevo, de las pruebas mencionadas. Todo el personal de control de acceso deberá portar de forma visible y permanente un distintivo que le acredite como tal.

Resulta preciso, puesto que está íntimamente relacionado con el control de acceso a espectáculos públicos que ha de realizar el personal contratado al efecto, mencionar los límites y formas de ejercicio del derecho de admisión. El artículo 24.2 de la Ley 17/1997 dispone que es un derecho ejercitable por los titulares de los establecimientos y los organizadores de espectáculos o actividades recreativas o personas en quienes deleguen, si bien no podrá emplearse para restringir el acceso de forma arbitraria o discriminatoria ni situar al usuario en condiciones de inferioridad, indefensión o agravio comparativo. El derecho de admisión deberá tener por finalidad impedir el acceso de personas que se comporten de manera violenta, que puedan producir molestias al público o usuarios o puedan alterar el normal desarrollo del espectáculo o actividad, de modo que las condiciones para el ejercicio del derecho de admisión deberán constar en lugar visible a la entrada de los locales, establecimientos y recintos. La norma autonómica prohíbe explícitamente el acceso a los establecimientos, espectácu- 
los públicos y actividades recreativas portando prendas o símbolos que inciten a la violencia, el racismo y la xenofobia. Téngase en cuenta, en todo caso, que el ejercicio del derecho de admisión de forma arbitraria o abusiva está tipificado como una infracción muy grave en el artículo 37.14 de la Ley 17/1997, de modo que serán responsables solidarios los titulares de los establecimientos y locales o de las respectivas licencias, y los organizadores o promotores de los mismos.

Parece evidente, ex artículo 5.1 b) Decreto 163/2008, que el control de acceso que debe realizar el personal habilitado ha de observar también el cumplimiento del artículo 25 de la Ley 17/1997 relativo a la protección del menor. Así, la meritada norma prohíbe la entrada y permanencia de menores de 16 años en bares especiales, así como en las salas de fiestas, de baile, discotecas y establecimientos similares con carácter general; y a los menores de 18 años, siempre que en ellas se venda o facilite el consumo de bebidas alcohólicas. También se prohíbe la entrada o participación de los menores de edad en los establecimientos, espectáculos y actividades enumerados en la Ley 6/1995, de 28 de marzo, reguladora de las Garantías de los Derechos de la Infancia y la Adolescencia, mientras que la participación de menores en otros espectáculos como artistas o intervinientes se regirá por la legislación laboral.

El personal de control de acceso también deberá velar, en una interpretación rigurosa de la norma, por que a los menores de 18 años que accedan a los establecimientos, espectáculos y actividades regulados en la Ley 17/1997 no se venda, sirva, regale ni permita el consumo de bebidas alcohólicas, quedando igualmente prohibida la venta de tabaco a menores de 18 años.

La Administración Pública encargada de vigilar el cumplimiento de todas las normas mencionadas y, por tanto, de que el personal de control de acceso en espectáculos y actividades recreativas cumpla las normas prescritas serán los Ayuntamientos, lo que no impide que la propia Comunidad de Madrid pueda realizar funciones inspectoras propias en el ámbito de sus competencias. Esas inspecciones pueden ser realizadas por funcionarios de las fuerzas y cuerpos de seguridad del Estado, de las policías locales o por funcionarios de la Comunidad de Madrid o de los Ayuntamientos debidamente acreditados y dotados de los medios técnicos adecuados para desempeñar su labor, ejerciendo en ese momento como agentes de la autoridad. Los organizadores de los espectáculos, los titulares de locales y establecimientos, así como los encargados de unos y otros, están obligados a permitir el acceso de los funcionarios debidamente acreditados al efecto para efectuar las inspecciones, estando igualmente obligados a prestarles la colaboración necesaria para el desarrollo de las mismas.

Hay que entender que la actuación profesional del personal contratado para el control de acceso a los establecimientos y actividades recreativas es responsabilidad de los titulares de los mismos, de forma solidaria con los organizado- 
res de los espectáculos y las actividades, puesto que el artículo 34.2 de la Ley 17/1997 así lo dispone por las infracciones que se cometan en dichos locales o establecimientos por quienes intervengan en el espectáculo o actividad y por quienes estén bajo su dependencia, entre los que hay que entender incluidos al personal de control de acceso. Todo ello con independencia, naturalmente, de la responsabilidad civil y penal en la que puedan incurrir personalmente dichos controladores de conformidad con la normativa civil y penal vigente.

Al margen del catálogo de infracciones que prevé la Ley 17/1997, cuya comisión debería evitar o prevenir, razonablemente, el personal de control de acceso a espectáculos y actividades recreativas puesto que sus facultades no se limitan a garantizar la seguridad en la entrada a los mismos, sino también en su interior, hay que destacar, por su relación directa con el objetivo principal que tiene la preservación de la seguridad, que el incumplimiento de estas condiciones cuando disminuya gravemente el grado de seguridad exigido en la normativa vigente y en las licencias o autorizaciones correspondientes está tipificado como una infracción muy grave en el artículo 37.8 de la meritada ley. Si el incumplimiento de esas condiciones no disminuye gravemente el grado de seguridad exigible la infracción pasa a ser grave, ex artículo 38.2 Ley 17/1997.

Las sanciones a imponer por la comisión de las infracciones muy graves abarcan desde una multa de 30.051 a $300.506 €$, clausura del local desde 6 meses y un día hasta 2 años, suspensión o prohibición de la actividad o espectáculos desde 6 meses y un día hasta 2 años, e inhabilitación para la organización o promoción de los espectáculos y actividades recreativas previstas en la ley desde 6 meses y un día hasta 2 años. En el caso de las infracciones graves, las sanciones tienen una graduación idéntica, pero de menor cuantía o duración.

El Decreto de la Comunidad de Madrid, que fue aprobado tras unos trágicos sucesos que devinieron en la muerte de un joven a las puertas de una discoteca madrileña, estableció un periodo de adaptación de tres meses desde su entrada en vigor para que todo el personal de control de acceso a estas salas y establecimientos cuenten con el certificado acreditativo mencionado en la norma, periodo de tres meses que vence el 6 de abril de 2009.

Las bases generales de las pruebas para la obtención del certificado acreditativo del personal de control de acceso a espectáculos públicos y actividades recreativas fueron aprobadas por Orden de la Consejería de Presidencia, Justicia e Interior de la Comunidad de Madrid, de 14 de enero de 2009, la cual también ha establecido el procedimiento de gestión, liquidación y recaudación de la tasa por derechos de examen, en la Academia de Policía Local de la Comunidad de Madrid, para la obtención de dicho certificado y efectúa la convocatoria de las citadas pruebas. La norma citada exige una convocatoria pública por Orden del consejero competente en materia de espectáculos públicos y actividades recreativas, convocatoria que será, al menos, anual. 
Las pruebas eliminatorias consisten en un test de conocimiento mediante la contestación, en un tiempo máximo de 60 minutos, de un cuestionario de 50 preguntas con cuatro respuestas alternativas sobre un programa que figura en el anexo de la Orden de 14 de enero de 2009 y que lo conforman seis temas sobre derechos y deberes fundamentales en la Constitución Española, sobre alguna tipología de delitos, sobre la tenencia de armas, sobre el derecho de admisión y libro de reclamaciones, sobre los horarios de los establecimientos públicos, sobre las limitaciones a la oferta de bebidas alcohólicas y tabaco y protección de menores de edad, y unas nociones básicas de las infracciones sobre prevención, extinción de incendios y salvamentos de la Comunidad de Madrid. La segunda prueba consiste en la realización de un test psicológico, con la duración que sea estrictamente necesaria.

La propia Orden aprovecha para realizar la convocatoria oficial de las pruebas, establecer la composición del tribunal calificador y recordar que la fecha y lugar de realización de las pruebas se hace pública en la Resolución dictada por la Academia de Policía Local de la Comunidad de Madrid por la que se aprueba la lista provisional de admitidos. La fecha fijada por la Consejería de Presidencia, Justicia e Interior de la Comunidad de Madrid para la realización de la primera prueba de conocimientos fue el pasado 14 de marzo de 2009.

Otras comunidades autónomas también cuentan con su propia normativa de habilitación y funciones del personal de control de acceso de determinados establecimientos de espectáculos y actividades recreativas, como Cataluña, que aprobó su respectivo Decreto el 20 de julio de $2004^{4}$, mucho antes que la Comunidad de Madrid, o la Comunidad Valenciana, que dictó el suyo apenas unos días antes que el de la comunidad madrileña, el 5 de diciembre de $2008^{5}$, con el fin de regular el derecho, la reserva y el servicio de admisión en los establecimientos públicos destinados a la realización de espectáculos públicos y actividades recreativas.

4 Decreto 348/2004, de 20 de julio, del Gobierno de la Generalidad de Cataluña.

5 Decreto 197/2008, de 5 de diciembre, del Consell. 
II. Jurisprudencia 
